\title{
Bank Interest Margin and Default Risk under Basel III Capped Capital Adequacy Accord and Regulatory Deposit Insurance Fund Protection
}

\author{
Chuen-Ping Chang ${ }^{1} \&$ Shi Chen ${ }^{2}$ \\ ${ }^{1}$ Department of Wealth and Taxation Management, Kaohsiung University of Applied Science, Kaohsiung City, \\ Taiwan \\ ${ }^{2}$ School of Economics, Southwestern University of Finance and Economics, Chengdu, China \\ Correspondence: Chuen-Ping Chang, Department of Wealth and Taxation Management, Kaohsiung University of \\ Applied Science, No.58, Shenzhong Rd., Yanchao Dist., Kaohsiung City 824, Taiwan. E-mail: \\ cpchang@cc.kuas.edu.tw
}

Received: September 10, 2014

Accepted: September 29, 2014

Online Published: November 4, 2014

doi:10.5430/ijfr.v6n1p14

URL: http://dx.doi.org/10.5430/ijfr.v6n1p14

\begin{abstract}
We study the optimal bank interest margin and default risk under the capped ratio schedule of government capital instruments in the Basel III Capital Adequacy Accord and the Deposit Insurance Fund arrangement program. We show that an increase in the capped ratio (a decrease in the capped government capital injection) increases the default risk in the bank's equity return at a reduced interest margin. Regulatory deposit insurance fund protection reinforces the reduced bank interest margin and the increased default risk. The capped ratio schedule as well as the fund protection program makes the bank more prone to loan risk-taking, thereby adversely affecting the stability of banking system. This paper suggests that the two means of government intervention in response to the recent financial crisis might be not appropriate for a bank in distress, particularly from the standpoint of bank failure.
\end{abstract}

Keywords: Basel III, deposit insurance fund, government capital injection, bank interest margin, default risk

\section{Introduction}

"At the Basel III meeting, the central bank's governors agree ... Government capital instruments that no longer quality as non-common equity Tier 1 or Tier 2 capital will be phased-out over a 10-year period beginning on January 1, 2013. Beginning in 2013, the recognition of these instruments as qualifying capital will be capped at $90 \%$ of the minimal amount of such instruments outstanding, with the cap declining by $10 \%$ in each subsequent year." Eubanks (2010). Such a schedule is called the capped ratio schedule of government capital instruments in the Basel III Capital Adequacy Accord (BCAA), which provides an opportunity to reexamine bank distress liquidity management related to the stability of the banking system. It is realized that a liquidity shock is an event where banks suddenly need resources.

Parallel to the development of the BCAA, there has been an ongoing discussion about the role of deposit insurance fund protection to influence bank behavior and make banks more robust against shocks, i.e., to "strengthen the soundness and stability of banks" in the Deposit Insurance Fund (DIF) protection. The Dodd-Frank Wall Street Reform and Consumer Protection Act (Dodd-Frank) requires that the DIF reserve ratio reach 1.35 percent by September 30, 2020 (Note 1). Hamilton (2013) reports that the reserve ratio is at 0.45 percent at the end of 2012 that the fund has much less than it required ratio of 1.35 percent of the deposits it insures and the Federal Deposit Insurance Corporation (FDIC) expects to reach goal by 2020. This also provides an opportunity to reinvestigate bank distress liquidity and banking stability. It is realized that sound funding arrangements are critical to the effectiveness of a deposit insurance system and to the maintenance of public confidence in it as well as in the banking system (Davis and Obasi, 2009).

The bank interest margin, that is the spread between the loan rate and the deposit rate, represents one of the principal elements of bank's net cash flows and earnings. This margin is often used in the literature as a proxy for the efficiency of financial liquidity. Prior research examines ex ante and ex post bank reactions to introduction of government capital injections but fails to consider the impacts of the capped ratio of BCAA and the regulatory deposit insurance protection on bank interest margin and further on bankruptcy prediction (for example, Lin et al., 
2012). This omission is critical because capital on bank performance is influenced by the capped ratio schedule of the BCAA and insurance fund on bank performance is also affected by the regulatory protection of the Dodd-Frank Act. The purpose of this paper is to incorporate a capped schedule into a regulatory barrier option framework of a bank in distress. It is shown that an increase in the capped ratio (a decrease in the capped government capital injection) increases the default risk in the bank's equity return at a reduced margin. Furthermore, regulatory insurance fund protection reinforces the reduced margin and the increased default risk. Government intervention in response to a financial turmoil as such makes the bank more prone to risk-taking, thereby adversely affecting the stability of the banking system.

Basel III received harsh criticisms from the banking industry and regulators (Note 2). We add to the criticism arguing that a decreasing cap on qualified capital under the regulatory capital requirement of Basel III makes banks more prone to risk-taking. The cap schedule in BCAA favors banks with a higher level of either private capital or government capital injections. Our argument is consistent with the demonstration of Eubanks (2010) that European banks are most critical of the proposal, arguing that Basel III favors U.S. banks because they have historically maintained a higher level of capital (Note 3). The cap schedule as such also favors a lower level of risk-based system of capital standards. Moreover, Basel III may conflict with countries' own regulatory efforts. For example, the United States (the Dodd-Frank Act) and Germany (the Act for Strengthening of Financial Markets and Insurance Supervision) have pushed for tougher rules and are moving ahead with additional regulatory restrictions on their financial institutions (Eubanks, 2010) (Note 4). The suggestion of Eubanks (2010) needs to be more nuanced due to our argument: regulatory insurance fund protection reinforces the effect of BCAA on the reduced interest margin and the increased default risk in the bank's equity return. However, Basel III is not a treaty, but is a work in progress that is far from completion, and the regulatory authorities may modify the agreement to suit their financial regulatory structures.

\section{The Framework}

Consider a bank that makes decisions in a single period horizon with two dates, 0 and $1, t \in[0,1]$. At $t=0$, the bank accepts $D>0$ dollars of deposits. The bank provides depositors with a market rate of return equal to the risk-free rate $R_{D}>0$ (Lin et al., 2012). The bank's shareholders contribute equity capital $K>0$ at $t=0$ with a required security-market rate of return $R>0$ on their investment, where $R>R_{D}$ reflects the scarcity of shareholders' wealth. The bank in distress participates in a government capital injection program that provides a source of capital $K_{g}>0$ at $t=0$ for the bank when public market alternatives are unavailable (Bayazitova and Shivdasani, 2012). A rate of return $R$ on the capital injection is required as well. Equity capital $K+K_{g}$ held by the bank is tied by regulation with a capped schedule to be a fixed proportion $q$ of the bank's deposits $K+(1-\alpha) K_{g} \geq q D$ where $0<\alpha<1$ is the capped ratio and $q>0$ is the required minimum capital-to-deposits ratio. According to BCAA, the recognition of $K_{g}$ as qualifying capital will be capped at $1-\alpha$ of the nominal amount of such outstanding government capital injection (Eubanks, 2010).

Loans of the bank $L>0$ belong to a single homogeneous class of fixed-rate claim that mature at $t=1$. The demand for loans is governed by a downward-sloping demand function $L\left(R_{L}\right)$ where $R_{L}>0$ is the loan rate chosen by the bank (Lin et al., 2012). Loans are risky because they are subject to non-performance. In addition to loans, the bank can also hold an amount $B>0$ of liquid assets on its balance sheet during $t \in[0,1]$. These assets earn the security-market interest rate of $R$. When the capital constraint is binding, the bank's balance-sheet liquidity constraint is given by:

$$
L+B=D+K+(1-\alpha) K_{g}+\alpha K_{g}=\left[K+(1-\alpha) K_{g}\right]\left(\frac{1}{q}+1\right)+\alpha K_{g}
$$

where the amount of $\alpha K_{g}$ no longer qualifies as non-common equity capital based on the regulation of BCAA.

The bank's objective is to set $R_{L}$ to maximize the expected market value of a path-dependent, barrier option function defined as in term of net worth at $t=1$, subject to Eq. (1). We argue that path dependency is a fundamental characteristic of corporate securities because the distressed bank's net equity can be knocked out whenever a legally 
binding barrier is breached (Brockman and Turtle, 2003, and Episcopos, 2008). A direct implication of this framework is that net equity will be priced as a down-and-out call (DOC) option. In this context, the market value of the bank's net equity can be written as (Note 5):

$$
S=\left[V N\left(d_{1}\right)-Z e^{-\delta} N\left(d_{2}\right)\right]-\left[V\left(\frac{H}{V}\right)^{2 b} N\left(b_{1}\right)-Z e^{-\delta}\left(\frac{H}{V}\right)^{2 b-2} N\left(b_{2}\right)\right]
$$

where

$$
\begin{gathered}
V=\left(1+R_{L}\right) L \text { with } d V=\mu V d t+\sigma V d W \\
Z=\left(1+R_{D}\right) D+(1+R)\left(K+K_{g}\right)-(1+R) B \\
=\frac{\left(1+R_{D}\right)\left[K+(1-\alpha) K_{g}\right]}{q \quad}+(1+R)\left(K+K_{g}\right)-(1+R)\left\{\left[K+(1-\alpha) K_{g}\right]\left(\frac{1}{q}+1\right)+\alpha K_{g}-L\right\} \\
\delta=R-R_{D} \\
d_{1}=\frac{1}{\sigma}\left(\ln \frac{V}{Z}+\delta+\frac{\sigma^{2}}{2}\right), d_{2}=d_{1}-\sigma \\
H=\beta Z, 0<\alpha<1, b=\frac{R-R_{D}}{\sigma^{2}}+\frac{1}{2} \\
b_{1}=\frac{1}{\sigma}\left(\ln \frac{H^{2}}{V Z}+\delta+\frac{\sigma^{2}}{2}\right), b_{2}=b_{1}-\sigma
\end{gathered}
$$

and where $V$ is the market value of the bank's loan repayments, with an instantaneous drift $\mu$, an instantaneous volatility $\sigma$, and a standard Wiener process $W$. The value of the loan repayments obeys the stochastic process subject to credit risk. We denote by $Z$ the book value of the net-obligation payments at $t=0$ that has maturity at $t=1$. The net-obligation payments are specified as the difference between the deposit payments and the equity capital payments to all equity holders and the repayments from the bank's liquid-asset investment. $\delta$ is the risk-free discounted rate. $H$ is the value of the bank asset that triggers bankruptcy (i.e., the barrier on knock-out value of the bank). $H$ is defined as $\beta Z$ where $0<\beta<1$ is the barrier-to-debt ratio (Brockman and Turtle, 2003). $N(\cdot)$ is the standard normal cumulative distribution function.

The first term [·] on the right-hand side of Eq. (2) is recognized as the excepted loan-payment value and present value of the net-obligation payments using the standard call option view of the bank. The second term [.] is recognized as bank bondholders (non-negative) claim. The barrier $H$ can be viewed as the value of loan repayments above which creditors cannot force dissolution. A related path-dependent option is the down-and-in call of the second term that is activated only if the barrier is breached. In other words, if the standard call framework is a good representation of reality, then the barrier-to-debt ratio should be zero (Note 6).

Using information about Eq. (2), we further illustrate one particular application of the DOC framework to the problem of bankruptcy prediction. The failure probability in the probability that $V$ will be less than $Z$ in our model. The valuation Eq. (2) implies a risk-neutral failure probability on the default risk in the bank's net equity returns over the interval from $t \in[0,1]$ that we can write as:

$$
P_{d e f}=N\left(a_{1}\right)+e^{a_{2}}\left(1-N\left(a_{3}\right)\right)
$$

where

$$
a_{1}=\frac{1}{\sigma}\left(\ln \frac{H}{V}-\delta+\frac{\sigma^{2}}{2}\right), a_{2}=\frac{2}{\sigma^{2}}\left(\delta-\frac{\sigma^{2}}{2}\right) \ln \frac{H}{V}, a_{3}=-\frac{1}{\sigma}\left(\ln \frac{H}{V}+\delta-\frac{\sigma^{2}}{2}\right)
$$

\section{Solution and Comparative Static Analysis}

Partially differentiating Eq. (2) with respect to $R_{L}$, the first-order condition is given by: 


$$
\begin{gathered}
\frac{\partial S}{\partial R_{L}}=\left[\frac{\partial V}{\partial R_{L}} N\left(d_{1}\right)+V \frac{\partial N\left(d_{1}\right)}{\partial d_{1}} \frac{\partial d_{1}}{\partial R_{L}}-\frac{\partial Z}{\partial R_{L}} e^{-\delta} N\left(d_{2}\right)-Z e^{-\delta} \frac{\partial N\left(d_{2}\right)}{\partial d_{2}} \frac{\partial d_{2}}{\partial R_{L}}\right] \\
-\left\{\left[\frac{\partial V}{\partial R_{L}}\left(\frac{H}{V}\right)^{2 b} N\left(b_{1}\right)+V(2 b)\left(\frac{H}{V}\right)^{2 b}\left(\frac{1}{H} \frac{\partial H}{\partial R_{L}}-\frac{1}{V} \frac{\partial V}{\partial R_{L}}\right) N\left(b_{1}\right)\right.\right. \\
\left.+V\left(\frac{H}{V}\right)^{2 b} \frac{\partial N\left(b_{1}\right)}{\partial b_{1}} \frac{\partial b_{1}}{\partial R_{L}}\right]-\left[\frac{\partial Z}{\partial R_{L}} e^{-\delta}\left(\frac{H}{V}\right)^{2 b-2} N\left(b_{2}\right)\right. \\
+Z e^{-\delta}(2 b-2)\left(\frac{H}{V}\right)^{2 b-2}\left(\frac{1}{H} \frac{\partial H}{\partial R_{L}}-\frac{1}{V} \frac{\partial V}{\partial R_{L}}\right) N\left(b_{2}\right) \\
\left.\left.+Z e^{-\delta}\left(\frac{H}{V}\right)^{2 b-2} \frac{\partial N\left(b_{2}\right)}{\partial b_{2}} \frac{\partial b_{2}}{\partial R_{L}}\right]\right\}=0
\end{gathered}
$$

We require that the second-under condition $\partial^{2} S / \partial R_{L}^{2}<0$ be satisfied. Inspection of the equilibrium of Eq. (4) reveals that a necessary condition for the optimal loan rate (and thus the optimal bank interest margin since $R_{D}$ is not a choice variable of the bank) is $\partial S / \partial R_{L}=0$ for net equity maximization. We further substitute the optimal $R_{L}$ to obtain the failure probability of the distressed bank in Eq. (3) staying one the optimization.

Consider next the impact on the default risk in the bank's equity return from changes in the capped ratio of BCAA. Differentiation of Eq. (3) evaluated at the optimal $R_{L}$ with respect to $\alpha$ yields:

$$
\frac{d P_{d e f}}{d \alpha}=\frac{\partial P_{d e f}}{\partial \alpha}+\frac{\partial P_{d e f}}{\partial R_{L}} \frac{\partial R_{L}}{\partial \alpha}
$$

where

$$
\frac{\partial R_{L}}{\partial \alpha}=-\frac{\partial^{2} S}{\partial R_{L} \partial \alpha} / \frac{\partial^{2} S}{\partial R_{L}^{2}}
$$

The first term on the right-hand side of Eq. (5) can be identified as the direct effect, while the second term can be identified as the indirect effect. The direct effect captures the change in $P_{\text {def }}$ due to an increase in $\alpha$, holding the optimal loan rate constant. The indirect effect arises because an increase in $\alpha$ decrease the bank's profit by $L\left(R_{L}\right)$ in every possible state. In general, the added complexity of a barrier option does not always lead to clean-cut results direct and indirect effects. However, we can certainly speak of tendencies for reasonable parameter levels corresponding roughly to Eq. (5). Computing changes in the option valuation of Eqs. (2) and (3) to changes in $\alpha$ is essential for bank interest margin management and failure prediction. The numerical examples provide intuition regarding problems at hand, for example, the comparative static analysis of Eq. (5).

\section{Numerical Exercises}

Unless otherwise indicated, the parameter values used in the following numerical exercises are assumed to be $R=3.5 \%, R_{D}=2.5 \%, K=20, K_{g}=10, q=9.0 \%$, and $\sigma=0.3$. Let $\left(R_{L} \%, L\right)$ change from (4.1, $300)$ to $(4.7,279)$ due to the conditions of $\partial L / \partial R_{L}<0$ and $\partial^{2} L / \partial R_{L}^{2}<0$. The value of $\alpha$ is from 0.1 to 0.6 due to the condition of $0<\alpha<1$ based on the capped ratio schedule of BCAA. The assumption of $R=3.5 \%>R_{D}=2.5 \%$ implies a binding case of capital adequacy requirement constraint (Wong, 1997). The assumption of $R_{L}>R_{D}$ indicates the positive bank interest margin as a proxy for the financial intermediation efficiency (Saunders and Schumacher, 2000). The assumption of $R_{L}>R$ demonstrates the scope of the earning-asset portfolio substitution (Kashyap et al., 2002). $q=9.0 \%$ implies that the capital-to-deposits ratio specification of capital adequacy requirement is consistent with the approach of the Basel (Eubanks, 2010). The numerical parameters presented above can be intuitively interpreted as being closely approaching a real state of a 
hypothetical bank.

Before proceeding with the analysis of the comparative static results of Eq. (5), we compute bank equity values of Eq. (2) at the barrier levels of $\beta=0.5$ and 0.9 with loan variability of $\sigma=0.3$ based on the empirical findings of Brockman and Turtle (2003) (Note 7). Note that as the barrier is raised from 0.5 to 0.9, the FDIC's contingent asset value is increased. Thus, a transfer of wealth from the bank to the FDIC takes place, implying the increased regulatory deposit insurance function protection. The computed findings of $\partial R_{L} / \partial \alpha$ are summarized in Table1.

Table 1. Values of $\partial R_{L} / \partial \alpha$ at various levels of barrier

\begin{tabular}{|c|c|c|c|c|c|c|c|}
\hline \multicolumn{8}{|c|}{$\left(R_{L} \%, L\right)$} \\
\hline$\alpha$ & $(4.1,300)$ & $(4.2,299)$ & $(4.3,297)$ & $(4.4,294)$ & $(4.5,290)$ & $(4.6,285)$ & $(4.7,279)$ \\
\hline \multicolumn{8}{|c|}{$\partial R_{L} / \partial \alpha(\%), \beta=0.5$} \\
\hline $0.1 \rightarrow 0.2$ & - & -1.0890 & -1.1121 & -1.1361 & -1.1619 & -1.1902 & - \\
\hline $0.2 \rightarrow 0.3$ & - & -1.0876 & -1.1093 & -1.1320 & -1.1563 & -1.1832 & - \\
\hline $0.3 \rightarrow 0.4$ & - & -1.0861 & -1.1065 & -1.1279 & -1.1508 & -1.1762 & - \\
\hline $0.4 \rightarrow 0.5$ & - & -1.0846 & -1.1038 & -1.1237 & -1.1453 & -1.1692 & - \\
\hline $0.5 \rightarrow 0.6$ & - & -1.0832 & -1.1010 & -1.1196 & -1.1397 & -1.1622 & - \\
\hline \multicolumn{8}{|c|}{$\partial R_{L} / \partial \alpha(\%$ o $), \quad \beta=0.9$} \\
\hline $0.1 \rightarrow 0.2$ & - & -0.2713 & -0.2768 & -0.2828 & -0.2894 & -0.2969 & - \\
\hline $0.2 \rightarrow 0.3$ & - & -0.2697 & -0.2749 & -0.2805 & -0.2868 & -0.2939 & - \\
\hline $0.3 \rightarrow 0.4$ & - & -0.2681 & -0.2730 & -0.2783 & -0.2842 & -0.2909 & - \\
\hline $0.4 \rightarrow 0.5$ & - & -0.2666 & -0.2711 & -0.2760 & -0.2816 & -0.2879 & - \\
\hline $0.5 \rightarrow 0.6$ & - & -0.2650 & -0.2692 & -0.2738 & -0.2790 & -0.2849 & - \\
\hline
\end{tabular}

Notes: Parameter values, unless stated otherwise: $R=3.5 \%, R_{D}=2.5 \%, K=20, K_{g}=10, q=9.0 \%$, and $\sigma=0.3$. The computed results of $\partial^{2} S / \partial R_{L}^{2}<0$ at $\beta=0.5$ and 0.9 confirm the second-order condition of Eq. (4).

The observed results from Table 1 are stated in the following proposition.

Proposition 1. An increase in the capped ratio of the capped government capital injection decreases the optimal bank interest margin. Regulatory deposit insurance fund protection reinforces the decreased margin.

In Table 1 , it is shown that $\partial R_{L} / \partial \alpha$ is consistently negative in sign and the negative effect at $\beta=0.5$ is less significant than that at $\beta=0.9$. Intuitively, as the capped ratio of the capped capital injection increases, the bank must now provide a return to a less loanable capital base. One way the bank may attempt to augment its total returns is by shifting its investments to its loan portfolio and away from the liquid-asset market. If loan demand is relatively rate-elastic, a larger loan portfolio at a reduced margin. In addition, the decreased margin size is larger when the barrier is high than when the barrier is low. A higher probability of hitting the barrier before the expiration date due the regulatory deposit insurance fund protection makes the bank more prone to loan risk-taking. The intuition is very straightforward. The distressed bank has an incentive to increase loan risk when it enjoys less protection from the government. Our findings are largely supported by Eubanks (2010). 
Table 2. Values of $P_{d e f}$ and $d P_{d e f} / d \alpha$ at various levels of barrier

\begin{tabular}{|c|c|c|c|c|c|c|c|}
\hline & $\left(R_{L} \%, L\right)$ & & & & & & \\
\hline \multirow[t]{2}{*}{$\alpha$} & $(4.1,300)$ & $(4.2,299)$ & $(4.3,297)$ & $(4.4,294)$ & $(4.5,290)$ & $(4.6,285)$ & $(4.7,279)$ \\
\hline & \multicolumn{7}{|c|}{$P_{d e f}, \beta=0.5$} \\
\hline 0.1 & 0.0237 & 0.0235 & 0.0233 & 0.0230 & 0.0228 & 0.0226 & 0.0224 \\
\hline 0.2 & 0.0237 & 0.0235 & 0.0233 & 0.0231 & 0.0229 & 0.0227 & 0.0224 \\
\hline 0.3 & 0.0238 & 0.0236 & 0.0234 & 0.0232 & 0.0230 & 0.0227 & 0.0225 \\
\hline 0.4 & 0.0239 & 0.0237 & 0.0235 & 0.0233 & 0.0230 & 0.0228 & 0.0226 \\
\hline 0.5 & 0.0240 & 0.0238 & 0.0235 & 0.0233 & 0.0231 & 0.0229 & 0.0227 \\
\hline \multirow[t]{2}{*}{0.6} & 0.0240 & 0.0238 & 0.0236 & 0.0234 & 0.0232 & 0.0230 & 0.0227 \\
\hline & \multicolumn{7}{|c|}{$d P_{d e f} / d \alpha:$ total effect $(\%), \beta=0.5$} \\
\hline $0.1 \rightarrow 0.2$ & - & 0.7369 & 0.7364 & 0.7382 & 0.7424 & 0.7493 & - \\
\hline $0.2 \rightarrow 0.3$ & - & 0.7387 & 0.7381 & 0.7399 & 0.7442 & 0.7511 & - \\
\hline $0.3 \rightarrow 0.4$ & - & 0.7404 & 0.7398 & 0.7417 & 0.7460 & 0.7529 & - \\
\hline $0.4 \rightarrow 0.5$ & - & 0.7421 & 0.7416 & 0.7434 & 0.7478 & 0.7548 & - \\
\hline \multirow[t]{2}{*}{$0.5 \rightarrow 0.6$} & - & 0.7438 & 0.7433 & 0.7452 & 0.7496 & 0.7566 & - \\
\hline & \multicolumn{7}{|c|}{$P_{d e f}, \quad \beta=0.9$} \\
\hline 0.1 & 0.7172 & 0.7149 & 0.7125 & 0.7101 & 0.7075 & 0.7049 & 0.7022 \\
\hline 0.2 & 0.7180 & 0.7157 & 0.7134 & 0.7109 & 0.7084 & 0.7058 & 0.7031 \\
\hline 0.3 & 0.7188 & 0.7165 & 0.7142 & 0.7118 & 0.7093 & 0.7067 & 0.7040 \\
\hline 0.4 & 0.7196 & 0.7174 & 0.7150 & 0.7126 & 0.7101 & 0.7075 & 0.7049 \\
\hline 0.5 & 0.7205 & 0.7182 & 0.7159 & 0.7135 & 0.7110 & 0.7084 & 0.7058 \\
\hline \multirow[t]{2}{*}{0.6} & 0.7213 & 0.7190 & 0.7167 & 0.7143 & 0.7118 & 0.7093 & 0.7066 \\
\hline & \multicolumn{7}{|c|}{$d P_{d e f} / d \alpha$ : total effect (\%),$\quad \beta=0.9$} \\
\hline $0.1 \rightarrow 0.2$ & - & 8.3226 & 8.3732 & 8.4530 & 8.5639 & 8.7084 & - \\
\hline $0.2 \rightarrow 0.3$ & - & 8.3218 & 8.3723 & 8.4522 & 8.5631 & 8.7076 & - \\
\hline $0.3 \rightarrow 0.4$ & - & 8.3209 & 8.3715 & 8.4513 & 8.5623 & 8.7067 & - \\
\hline $0.4 \rightarrow 0.5$ & - & 8.3200 & 8.3706 & 8.4505 & 8.5614 & 8.7058 & - \\
\hline $0.5 \rightarrow 0.6$ & - & 8.3191 & 8.3697 & 8.4496 & 8.5605 & 8.7050 & - \\
\hline
\end{tabular}

Notes: Parameter values, unless stated otherwise: $R=3.5 \%, R_{D}=2.5 \%, K=20, K_{g}=10, q=9.0 \%$, and $\sigma=0.3$.

The computed results obtained from Table 2 are summarized in the following proposition.

Proposition 2. An increase in the capped ratio of the capped government capital injection increases the default risk in the bank's equity return. Regulatory deposit insurance fund protection significantly reinforces the increased default risk.

In Table 2, we demonstrate through simulations that the effect of $\alpha$ on $P_{d e f}$ is consistently positive in sign as shown in the second and fourth panels, and the effect at $\beta=0.9$ has much more significant than that at $\beta=0.5$. When the additional capital from a government assistance program is not totally counted in Tier 1 capital or Tier 2 capital, the new regulation as such makes the bank less prudent and more prone to asset risk-taking and thus increasing the bank's default probability, and adversely affecting the stability of the banking system. Our finding adds a criticism of the BCAA capped ratio schedule by focusing on bank capitalization and lending behavior. For example, the French Bankers Association assessment is that the adjustment to Basel III is unworkable because it would result in a Tier 1 capital shortage of between \$2.7 trillion and \$4.7 trillion for Eurozone courtiers alone (Note 8). In addition, these positive effects on bank default risk are reinforced by the regulatory deposit insurance fund protection. Not surprisingly, public outcries for more bank capital tend to be greater after the financial crisis, and 
post-crisis reform proposals tend to focus on how capital regulation and deposit insurance fund arrangement should adapt to prevent future crisis.

\section{Conclusion}

The barrier options theory of corporate security valuation is applied to the contingent of a bank under a capped ratio schedule of government capital injections in BCAA. Moreover, the modeled barrier structure can explicitly capture the regulatory issue of deposit insurance fund protection in the spirit of the Dodd-Frank Act. Results are derived that should be of interest to investors, bank managers, and policy makers. For example, an increase in the capped ratio (equivalently a decrease in the qualified regulatory capital) when the government capital injection is increased has a negative effect on bank interest margin, and further has a positive effect on default risk. Furthermore, these effects become more significant when the regulatory deposit insurance fund protection is increased. In conclusion, it is shown that the barrier option model is intimately relevant to regulation under the BCAA and insurance fund protection under the Dodd-Frank Act.

Of course, we may question whether government capital injections are a cost-efficient solution and if alternative strategies such as government guaranteed debt issuance programs and/or purchases of distressed assets by the government would have yielded better outcomes. Such concerns are beyond the scope of this research and so are not addressed here. What this research does demonstrate, however, is the important role played by BCAA associated with the Dodd-Frank Act in affecting the stability of the banking system.

\section{References}

Bayazitova, D., \& Shivdasani, A. (2012). Assessing TARP. Review of Financial Studies, 25, 377-407. http://dx.doi.org/10.1093/rfs/hhr121

Berger, A.N., \& Bouwman, C.H. (2013). How does capital affect bank performance during financial crises? Journal of Financial Economics, 109, 146-176. http://dx.doi.org/10.1016/j.jfineco.2013.02.008

Bhattacharya, S., Plank, M., Strobl, G., \& Zechner, J. (2002). Bank capital regulation with random audits. Journal of Economic Dynamics and Control, 26, 1301-1321. http://dx.doi.org/10.1016/S0165-1889(01)00045-8

Brockman, P., \& Turtle, H.J. (2003). A barrier option framework for corporate security valuation. Journal of Financial Economics, 67, 511-529. http://dx.doi.org/10.1016/S0304-405X(02)00260-X

Chen, S., Chang, C.P., \& Keh, K.P. (2014). A note on bank default risk and delivery channel strategy under deposit insurance fund protection. International Journal of Financial Research, forthcoming.

Davis, E.P., \& Obasi, U. (2009). The effectiveness of banking supervision. Economics and Finance Working Paper Series, Working Paper No. 09-27, Brunel University.

Episcopos, A. (2008). Bank capital regulation in a barrier option framework. Journal of Banking and Finance, 32 , 1677-1686. http://dx.doi.org/10.1016/j.jbankfin.2007.11.018

Eubanks, W.W. (2010). The status of the Basel III Capital Adequacy Accord, Congressional Research Service, 7-5700. Retrieved from www.crs.gov; R41467.

Hamilton, J. (2013). FDIC deposit insurance fund hits $\$ 33$ billion after 2009 deficit. Retrieved from http://www.bloomberg.com/news/2013-04-11/fdic-deposit-insurance-fund-hits-33-billion-after-2009-deficit.htm 1

Kashyap, A.K., Rajan, R.G., \& Stein, J.C. (2002). Banks as liquidity providers: An explanation for the coexistence of lending and deposit-taking. Journal of Finance, 57, 33-73. http://dx.doi.org/10.1111/1540-6261.00415

Kashyap, A.K., Stein, J.C., \& Hanson, S. (2010). An analysis of the impact of "substantially heightened" capital requirements on large financial institutions. Mimeo. Retrieved from http://www.hbs.edu/faculty/Pages/item.aspx?num=41199

Lin, J.H., Chang, C.P., \& Hung, W.M. (2012). A note on bank bailout: Equity quality and direct equity injections. Applied Economics Letters, 19, 947-951. http://dx.doi.org/10.1080/13504851.2011.608636

Mazumdar, S.C. (1997). Regulatory monitoring, closure costs and bank moral hazard behavior. Journal of Regulatory Economics, 12, 267-289. http://dx.doi.org/10.1023/A:1007953912853

Mehran, H., \& Thakor, A.V. (2011). Bank capital and value in the cross-section. Review of Financial Studies, 24, 1019-1067. http://dx.doi.org/10.1093/rfs/hhq022 
Pruzin, D. (2010). Central bank governors approve hike in minimum capital requirements for banks, BNA Banking Daily-Breaking News, September 12, 1.

Saunders, A., \& Schumacher, L. (2000). The determinants of bank interest rate margins: An international study. Journal of International Money and Finance, 19, 813-832. http://dx.doi.org/10.1016/S0261-5606(00)00033-4

Wong, K.P. (1997). On the determinants of bank interest margins under credit and interest rate risks. Journal of Banking and Finance, 21, 251-271. http://dx.doi.org/10.1016/S0378-4266(96)00037-4

\section{Notes}

Note 1. Dodd-Frank Wall Street Reform and Consumer Protection Act, Pub. L. No. 111-203, § 334(d), 124 Stat. 1376, 1539 (2010) (codified at 12 U.S.C. § $1817(\mathrm{nt})$ ).

Note 2. For example, the Institute of International Finance warned in June 2010 that the Basel III proposal would require that these large banks raise $\$ 700$ billion in common equity and issue $\$ 5.4$ trillion in long term debt over next five years to meet the standards, which would cause a 3\% decline in the U.S. GDP compared with what it would otherwise be in five years (Pruzin, 2010). JP Morgan Chase and Morgan Stanley argued that the Basel III proposal would significantly reduce the availability of credit to the U.S. economy (see http://www.bis.org/publ/bcbs165/jpmorganchase.pdf and http://www.bis.org/publ/bcbs165/morganstanley.pdf). Deutsche Bank's comment was that the timetable was too short to increase common equity because the prospects for future profits, the main source of common equity, are not good for the short (see http://www.bis.org/publ/bcbs165/deutschebankcap.pdf).

Note 3. The recent financial crisis raises fundamental issues about the role of bank equity capital, particular from standpoint of bank survival (see, for example, Kashyap et al., 2010, Mehran and Thakor, 2011, and Berger and Bouwman, 2013). We add to the literature on bank equity capital by providing a formal illustration of BCAA.

Note 4. Literature on protecting the insurance funds and the stability of the banking system includes, for example, Mazumdar (1997), Bhattacharya et al. (2002), Episcopos (2008), and Chen et al. (2014). Our paper may be viewed as complementary to these studies by adding the issue of BCAA.

Note 5. For simplicity, we consider only the case of a constant barrier, $H=\beta Z$ in Eq. (2). Brockman and Turtle (2003) develop a model of firms with exactly this structure.

Note 6. However, Brockman and Turtle (2003) present strong evidence that firm-specific barriers are non-zero across firms in their empirical sample.

Note 7. The average barrier estimates by year is form 0.5900 with a corresponding standard deviation of 0.2227 to 0.8395 with a corresponding standard deviation of 0.1405 , and the average asset volatility is 0.2904 with a corresponding standard deviation of 0.2608 in the empirical findings of Brockman and Turtle (2003).

Note 8 . See the assessment at http://www.asf-france.com. 